EGU21-602

https://doi.org/10.5194/egusphere-egu21-602

EGU General Assembly 2021

(c) Author(s) 2021. This work is distributed under

the Creative Commons Attribution 4.0 License.

\title{
Effects of biochar ageing on the remediation potential of trace- element polluted soils
}

\author{
José María De la Rosa ${ }^{1}$, Paloma Campos ${ }^{1}$, Ana Z. Miller ${ }^{1,2}$, Marta Velasco-Molina ${ }^{1}$, Águeda Sánchez- \\ Martín ${ }^{1}$, Araceli De la Rosa1, and Heike Knicker ${ }^{1}$ \\ ${ }^{1}$ Instituto de Recursos Naturales y Agrobiología de Sevilla, Consejo Superior de Investigaciones Científicas, IRNAS-CSIC. Av. \\ Reina Mercedes 10. 41012, Seville, Spain. *) jmrosa@irnase.csic.es \\ ${ }^{2}$ Laboratorio Hercules, University of Évora, Largo Marquês de Marialva 8, 7000-809, Évora, Portugal.
}

Trace elements are toxic at high concentrations and present long-term persistency in the environment. Biochar, the solid carbonaceous residue produced by pyrolysis of biomass, has been proven to have great potential to adsorb trace elements [1]. Biochar efficiency for trace element adsorption depends on biochar properties, which are affected by feedstock and pyrolysis conditions $[2,3]$. Nevertheless, the effect of biochar ageing on trace element immobilization is still not well understood. To fill this gap, a 2-years field experiment was performed next to the Guadiamar River (SW Spain), which was polluted in 1998 due to the breakage of a mining waste pond, causing the dumping of millions of tonnes of toxic sludge. Consequently, the soils studied have acid $\mathrm{pH}$ and high concentrations of trace elements ( $\mathrm{As}, \mathrm{Ba}, \mathrm{Cu}, \mathrm{Pb}$ and $\mathrm{Zn}$ ). For this experiment, the soils were amended with $8 \mathrm{t} \mathrm{ha}^{-1}$ of rice husk and olive pit biochars. Additionally, biochars produced from rice husk, olive pit and wood chips were buried in these polluted soils using permeable bags. After 2 years, soil and biochar properties as well as trace element contents (total and extractable) were determined. The ageing process reduced the aryl $\mathrm{C}$ signal in biochar samples as revealed by cross polarization magic angle spinning ${ }^{13} \mathrm{C}$ nuclear magnetic resonance (CPMAS NMR) analysis. O-containing groups in aged biochar were detected by Fourier Transform mid-Infrared Spectroscopy (FT-IR). Although biochars effectively adsorbed trace elements from the polluted soils, the contents of $\mathrm{CaCl}_{2}$-extracted trace elements in the soils were not modified. This is probably due to the extremely high total abundance of trace elements in these soils, which permit a quick remobilization of bound metals refilling of the extractable pool, and replacing the heavy metals adsorbed by biochar. Consequently, the content of extractable trace elements in these polluted soils may only be reduced by a periodic application of high amounts of biochars.

\section{References:}

[1] Amin, M.T., Alazba, A.A., Shafiq, M., 2018. Chem. Eng. J. Arab. J. Sci. Eng. 43, 5711-5722.

[2] Campos, P., De la Rosa, J.M., 2020. Sustainability 12, 6025.

[3] Campos, P., Miller, A.Z., Knicker, H., Costa-Pereira, M.F., Merino, A., De la Rosa, J.M., 2020. Waste Manag. 105, 256-267. 
Acknowledgements: The former Spanish Ministry of Economy, Industry and Competitiveness (MINEICO), AEI/FEDER and CSIC are thanked for funding the project CGL2016-76498-R. J.M. De la Rosa acknowledges MINEICO for funding his "Ramón y Cajal" contract. P. Campos thanks "Fundación Tatiana Pérez de Guzmán el Bueno" for funding her PhD. 